\title{
AN APPLICATION OF CAPACITY DESIGN PHILOSOPHY TO GRAVITY LOAD DOMINATED DUCTILE REINFORCED CONCRETE FRAMES
}

\author{
T. Paulay*
}

\begin{abstract}
Indiscriminate application of the capacity design philosophy can lead to unnecessary or indeed absurd conservatism in the earthquake resistant design of gravity load dominated ductile reinforced concrete frames. Low-rise framed buildings are typical examples. The origin of excessive potential strength with respect to lateral loading is discussed and proposals are made to establish an acceptable upper bound for lateral load carrying capacity in such frames. A technique is presented by which the successive formation of potential plastic hinges, involving partial beam sway mechanisms, can be conveniently assured. While retaining the requirements for energy dissipation in beams, it is postulated that at an acceptable high level of lateral loading the formation of storey mechanisms, necessary to complete the frame sway mechanism, should be tolerable. Examples are given to illustrate the determination of design quantities for bending moments, shear and axial forces for both, beams and columns.
\end{abstract}

\section{INTRODUCTION}

In low rise ductile reinforced concrete frames, particularly in those with long span beams, often gravity rather than seismic load requirements will govern the design strength of beams.

In capacity design normally it is necessary to evaluate the overstrength flexural capacity $(1)$ of both potential plastic beam hinges in each span in order to evaluate the maximum attainable moment input into the columns of the frame. This procedure, applicable to low rise buildings with more than two storeys, in which the "weak beam - strong column" design philosophy is pursued, may produce column design moments and shear forces that are unnecessarily large. The reason for this is the large potential beam strength and the consequent lateral load required to produce in the beam sway mechanism plastic hinges with positive (sagging) rotations in a region largely dominated by a negative gravity moment. Under these circumstances the magnitude of the lateral load, required to produce a complete beam hinge sway mechanism in each span of a bent, may be several times that intended by the loading code $(2)$. If the designer insists on the full execution of capacity design in order to ensure that column yielding will generally occur after the formation of beam sway mechanisms, the columns would have to be designed for an even larger lateral load.

Skillfully applied moment redistribution (3) may considerably reduce the unintended potential lateral load carrying capacity of such frames. Therefore designers should make full advantage of the benefit that results from ductile behaviour that is expected to eventuate at and above lateral design load levels. To relocate positive (sagging) potential plastic hinges from column faces is an effective way to reduce the lateral load resistance of the beams.

* Professor of Civil Engineering, University of Canterbury, Christchurch.
This will be illustrated in one of the subsequent examples. However, in many cases the most meticulous allocation of beam hinge strengths will not offset the excess potential lateral load resistance, and in such cases it will be found that the columns would need to be provided with unrealistic extreme lateral load resisting capacity, if it is decided that they must possess at all times strength in excess of that of the beams.

It is proposed that in frames, in which design considerations for gravity load result in potential strength to resist lateral load much in excess of that stipulated by the loading code $(2)$, some limitation on the required minimum strength of columns be introduced. In certain cases it may be shown that with the development of the negative (hogging) plastic hinge in each span, that is with an incomplete beam sway mechanism, seismic strength well in excess of the required minimum can be developed. At such high level of lateral load resistance, considerably reduced demand for energy dissipation is to be expected. This reduced energy demand may well be supplied by a lesser number of plastic hinges. A moment input into columns, at a level which is below the overstrength capacity of the beams, may therefore be considered. This implies that at an acceptable high level of lateral load resistance, column hinges rather than additional beam hinges, with positive rotations, will need to form to complete the sway mechanism of the frame.

\section{QUANTITATIVE EVALUATION OF THE POTENTIAL STRENGTH OF BEAM SWAY MECHANISMS}

A convenient means of expressing the contribution of strength of beams at any floor to lateral load resistance, is the summing of the relevant beam moment inputs into the columns at that level of a bent. This is essentially the same as summing the column shear forces generated, when the beam strengths in the bent are developed, in order to arrive at the total storey shear. 
As Fig. 1(b) illustrates, the total lateral design load induced moment at 4 columns ( $A$, $B, C$ and $D)$ of a symmetrical bent with a three-span continuous beam at a particular floor is

$\Delta \vec{M}_{A}^{E}+\Delta \vec{M}_{B}^{E}+\Delta \vec{M}_{C}^{E}+\Delta \vec{M}_{D}^{E}=\Sigma \Delta \vec{M}_{i}^{E}$

This also represents the required total moment input from beams into the four columns. These beam moments at column centrelines represent the dependable strength for lateral design earthquake load in the given direction, $\vec{*}$, stipulated for that structure by a loading code (2). The actual strength of the beam, which may have been controlled by gravity load considerations, may then be related to this minimum lateral load requirements. Eq. (1), with the aid of the average beam overstrength factor, " $\psi_{0}$, avg" which is defined subsequently.

For the beam of a bent shown in Fig. 1 the suitably factored gravity load induced moments, derived from conventional elastic analysis (Fig. I(a)), are combined with the earthquake moments, also obtained from an elastic analysis, as shown in Fig. I(c). To avoid possible confusion of issues, at this stage no moment redistribution has been applied in the illustrative structure.

It may be assumed that these moments (Fig. I(c)) governed the amount of flexural reinforcement in the beams and accordingly the demand for the dependable $(4)$ flexural capacities has been met exactly. To satisfy code $(5,1)$ requirements for ductile sections, positive (bottom) reinforcement at the support of all beams has been provided to sustain $50 \%$ of the negative moment requirements at the same sections. It is this requirement that leads normally to excessive lateral load carrying capacity in gravity load dominated frames.

The example in Fig. I is presented to illustrate changes of moment patterns at various steps of the proposed procedure, while satisfying equilibrium and continuity criteria. For this reason it is convenient in this example and the remainder of the paper to refer to centre line moments rather than to moments at the faces of members which would control in actual design the lateral load carrying capacity of such members.

To satisfy capacity design requirements the flexural over-capacities at the potential plastic hinge sections need to be evaluated. These beam sections are first assumed to be at the columns. Typically the flexural overcapacity at a section is $1.25 / 0.9=1.39$ times the dependable capacity when Grade 275 flexural beam reinforcement is used $(4)$. These are shown by the shaded areas in Fig. 1(d). It should be noted that large positive overcapacity moments are possible at the columns because large (i.e. $50 z$ of negative steel requirements) amount of bottom steel has been provided. It need also be assumed that excess bottom reinforcement is available within all spans so that positive (sagging) plastic rotation can occur adjacent to the columns only.

Now the maximum potential lateral load resistance of the beam sway mechanisms for the entire bent can be computed by suming the maximum potential moment inputs into the columns, i.e. $\sum \Delta \vec{M}_{i}$, for the chosen direction (E) of earthquake loading.

With reference to $\mathrm{Fig}$. I(d), it is seen that

$$
\begin{aligned}
\sum \Delta \vec{M}_{i}^{O}=p \overrightarrow{\mathrm{M}}_{A}^{\circ} & +n \vec{M}_{B}^{O}+p \vec{M}_{B}^{\circ}+n \vec{M}_{C}^{\circ}+p \vec{M}_{C}^{\circ} \\
& +n \vec{M}_{D}^{O}=\Sigma \mathrm{pM}_{i}^{O}+\sum n \vec{M}_{i}^{\circ}
\end{aligned}
$$

where:

$\overrightarrow{\mathrm{M}}$

is the beam overstrength flexura capacity that could be developed at column centre lines by lateral load acting in the given direction

$A, B, C, D, i$ identify the par:- cular column

$\mathrm{p}, \mathrm{n}$

signify that positive (p) or negative ( $n$ ) moments, involving the yielding of the bottorn or top beam flexural reinforcement respectively at the section, are being considered.

The average beam overstrength factor for the entire bent, expressing the maximum potential lateral load capacity (Eq. (2)) in relation to the code required dependable lateral load strength (Eq. (1)), may now be defined as

$\vec{\psi}_{0, \text { avg. }}=\sum \Delta \overrightarrow{\mathrm{M}}_{i}^{\circ} / \sum \Delta \overrightarrow{\mathrm{M}}_{i}^{E}$

The magnitude of the average beam overstrength factor for the bent will be compared subsequently with the maximum value, $\psi_{0}$, avg.max.
that may not need to be exceeded. The considerations leading to the quantitative establishment of an upper bound value of the average overstrength factor for various classes of buildings are presented in section 4 .

If $\psi_{0}$ gvg." relevant to the specified direction of loading, is smaller than $\psi_{0}$, avg.max. given by Eq. (9), then the full beam overstrength factors $\psi_{0}$, at each column can be used in afriving at the final column design moments $(6)$. However, if $\psi_{0}, a v g$ is found to be larger than $\psi_{0}$, avg.max. overstrength capacity of the beams should not be expected to be developed. In that case the column design moments could be limited to those corresponding with the maximum average beam overstrength capacity factor $\psi_{\text {o, avg.max. . Eq. (9). The latter procedure }}$ would then imply that at the acceptable high level of lateral loading, column yielding or hinging should be expected, while only a partial beam sway mechanism in a particular bent has formed. The procedure proposed here rests on the premise that up to the level of loading corresponding with $\psi$,avg.max. considerable amount of energy is dissipated

* This has been defined in Ref. (6) but for convenience it is reproduced here. "The beam overstrength factor, $\psi_{0}$, is the ratio of the sum of the flexural overstrengths developed by the beams, as detailed, and the sum of the flexural strength required by the code specified lateral loading, both sets of values being related to the centre line of a column." It is relevant to one particular direction of the applied lateral load. 
by at least one plastic hinge in the critical negative moment locality of each span of the bent. This precludes the formation of "soft storey mechanisms" in which no beam hinges develop.

\section{LIMITING THE BEAM DESIGN MOMENT INPUTS INTO COLUMNS}

A brief study of frame behaviour under lateral load (Fig. I(e)) or the bending moment pattern, shown in Fig. I(d), will reveal that normally plastic hinges in the beams will occur first in the negative moment regions. It is also evident from Fig. I(e) that very considerable plastic hinge rotations at these negative moment hinges may occur before positive (sagging) plastic hinges, near the opposite ends in each span of the beam, can develop. Frequently the development of these positive hinges may be possible only if lateral forces equal or larger than $\psi_{0}$ avg max times the code load is applied. For this very severe loading case the development of all positive (sagging) plastic hinges in the beams should not be expected. Indeed the beam capacities in these potential positive hinge areas should be limited so that their contribution to lateral load resistance of the beam does not result in excessive capacity of the beam sway mechanism shown in Fig. $l(e)$.

To prevent excessive beam strengths with respect to lateral load from developing, it should be sufficient to require that at this high level of load resistance in each span of the continuous beam:

(a) A negative plastic hinge develops at the ideal capacity of the critical section of that hinge. This capacity may be taken as $90 \%$ of the flexural overstrength. Because of the large lateral load resistance of the frame within the elastic range of response there appears to be no need to consider in design the flexural overcapacity of beams in this class of structure.

(b) Positive moments at the other ends of spans develop at a sufficient intensity only to satisfy the requirements that the lateral load capacity of the bent is the intended maximum, i.e. $\psi_{0}$, avg. $\max ^{\Sigma \Delta} \overrightarrow{\mathrm{M}}_{i}^{\mathrm{E}}$. This may require that at some regions the ideal positive moment hinge capacity will also need to be attained.

It follows from these considerations that the sum of the positive end-moments, required to be developed before the onset of yielding in the adjacent columns, be

$\sum \mathrm{p} \vec{M}_{i}=\psi_{0, \operatorname{avg} \cdot \max } \cdot \sum \Delta \overrightarrow{\mathrm{M}}_{i}^{\mathrm{E}}-0.9 \sum \mathrm{n} \overrightarrow{\mathrm{M}}_{i}^{\circ}$

i.e. the total intended capacity of the bent less the contribution of the negative plastic beam hinges.

In order to generate positive moments at the ends of the spans, opposite to those at which negative moment hinges have been assumed to have formed, the (negative) gravity moment at such localities (emphasised in equations by the letter p) $\mathrm{pM}_{\mathrm{i}}^{\mathrm{G}}$, will need to be reduced or indeed reversed. To achieve this the sum of the moments to be applied to potential positive plastic hinge regions of the bent must be
$\overrightarrow{\mathrm{X}}=\Sigma \mathrm{p}_{i}-\sum \mathrm{pM}_{i}^{\mathrm{G}}$

The negative sign in Eq. (5) signifies the fact that the opposite of the gravity moments, normally negative, at these ends need be applied.

When applying and distributing this moment input, $\vec{x}$, among positive end-moment regions, the stiffness of each span need also be taken into account. This is because at this load level the beam, with the exception of the negative hinge region, is expected to respond within elastic limits. Accordingly the positive moment input, $\vec{x}$, may be distributed among spans in proportion of the relative beam flexural stiffness, $k_{i}=I_{i} / I_{i}$.

With this distribution the final design moments in the potential positive hinge regions of each span may be obtained from:

$\mathrm{pM}_{i}=\mathrm{pM}_{i}^{G}+\frac{\mathrm{k}_{i}}{\sum \mathrm{k}_{i}} \overrightarrow{\mathrm{x}}$

It is now necessary to compare this moment with the ideal flexural capacity that has been provided at that end of the beam. Eq. (6) is valid only if

$\overrightarrow{\mathrm{M}}_{i}=0.9 \mathrm{p} \overrightarrow{\mathrm{M}}_{i}^{\mathrm{O}}$

When Eq. (7) is satisfied, the potential positive plastic hinge region of the span is either elastic or a hinge at ideal strength, equal to 0.9 times the flexural overstrength, has just been attained.

However, when Eq. (7) is not satisfied, the sum of the moments in excess of the ideal flexural capacities of all potential positive plastic hinges that are affected, $\vec{\Delta} \mathrm{x}$, need be redistributed to the remaining positive potential plastic hinges, at which Eqs. (6) and (7) have been satisfied. At such potential positive hinges the final design moment may be obtained from

$\mathrm{p}_{\vec{M}_{i}}=\mathrm{pM}_{i}^{G}+\frac{\mathrm{k}_{i}}{\sum \mathrm{k}_{i}} \overrightarrow{\mathrm{X}}+\frac{\mathrm{k}_{i}^{*}}{\sum \mathrm{k}_{i}^{*}} \Delta \overrightarrow{\mathrm{X}}$

In this equation $k_{1}^{*}$ denotes the stiffness of those beams (spans) in which only negative plastic hinges have formed, i.e. those which at this stage of the loading are still elastic.

In order to check that the original criteria, Eq. (4), is satisfied, it is advisable to compute

$\sum \mathrm{p}_{i}+0.9 \sum \mathrm{nM}_{i}^{\mathrm{O}}=\psi_{0, \operatorname{avg} \cdot \max .} \sum \Delta \overrightarrow{\mathrm{M}}_{i}^{\mathrm{E}}$

Typical design moments, so obtained are shown by the dashed curves in Fig. 1(d). It may be noted that the positive moments in all spans as well as at the supports are reduced. Consequently the moment inputs into columns, $\Delta \vec{M}_{i}$, design, to be resisted at their ideal strength capacity, are also limited.

The sequence in beam hinge formation is irrelevant to the design. However, it may be noted that in a gravity load 
domnated frame, such as shown in Ejg. 1, generally the negative beam hinges will Form first and positive platulo hinges, if any, will deverop iatex. mhis sequence may

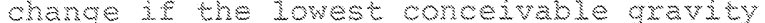
1oad, 1.e. 0.90, is consadered together with the iateral sejwic displacements. In this case a posituve plastic hinge may fomm first. typlcaliy in shor exterior spans, before a negative plastic hange develops, typhaily at an kntextor support. In such frames, desigmed in accordance with this proposal. yielding of an intextor colum may commence before any beam hirges have fommed adjacent to it. However, im such frames also some beam hinging will precede colum yielding. The maximum lateral load capactity w1 not be kess than wo,avo.max. thmes the code required seismic 102 . merefore in the dexivation of the maximum colum desion moments the load combination $(0.9 D+E)$ or $(0.9$ is) showld not normally need to be constaered.

\section{AN ESTMMATE OF THE MAXMMUM DESTRED GRRNGTH OF DUCFML RRAMES}

Resent New zealand setsmic load provisions for ductive structures are based on the concept that the dependable strength of the structure with respect to lateral $10 a d$ be of the ordex of one guartex of that which would be reguired to resist intertia rorces during a fuliy elastic seismic dynamic response(2). wherefone it does not appear to be necessary to provide deliberately strength in any part of a ductile frame to resist lateral 1oad, which is in excess of Four thes that stipuated by the Joaning code $(2)$. Indeed foundations are required to be designed for considerably less lateral load (2). The maximum strength that may be deswred to be developed in the columns of such trames could ever be less, provided that the detaling of such members is for ductisity.

Tn dexiving an acceptable rlexural capacity for columm, which should not need be exceeded in such frames, the following Eactors should be considered:

(i) me sum of the colum flexural strengths at any level of a Frame of a class TIT Buidung( 2$)$, with an Importance Factor, $T$, of ${ }^{2} .0(2)$, should not need to exceed say 3.5 thmes the code required sedsmic flexura strengths. At this hich level of loadng it showld be sufficient to aseune that the probable wexural stremgth of the columx sections will be avaluble. This may be assumed to be approximately 1.25 thmes the ideai capacity(4), ox 0.9 thmes the overw stremgth.

(ij) Ghould columm yiending ocour at this interstey of lateral seismie loading, littie ductikty demand is to be expected in the colum, Consequentyy transient simutaneous yielding at the top and the bottom of colums in a storey should be acceptable. It is to be moted that such a storey mechandsm is only a minor source of energy dissipation In the whole system. However, as a corollary. the design procedure must ensure that at least a partial beam sway mecharism wil form at eack lower storey before the possibin... ity of a storey mechanism would arise.

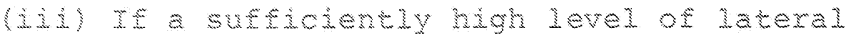
sejsmic load is considered, as proposed in
Whis paper, there appears to be mo reed to provide for reserve strength that would catex for aymamio magnitication of colum moments $(6)$.

(Av) mhe purpose of using hmportamee factors larger than unity for public or other buklings of special puxpose is, at one hard, to provide a higher degree of protection against collapse, and on the other, to reduce the ductintty demand for a given excitation and hence the Mkely structura. damage. mhereby the functionsmo of the special purpose building after ax earthouake is enhanced.

whe proposed apper bound fox lateray

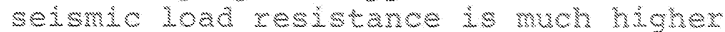
thar that envisaged by code provisions for any type of ductile structure. kence the rsik for collapse is muck wess. Also a gravity load dominated ductile trame. destoned in accordance with these sxcgestions, wis resist largex rorees whthin the elastic domain of response and hemce the excursions beyond yield level axe Mkely to be small. mherefore reduced ductinfty demand and conseguent reduction of structural damage car be expected. me loadra envisaged kn fins proposa exceeds that sthpulated(2) even for a class I building. For these reasons it appears suttichent to set the same desired wpper bound of latera $10 a d$ resistance box aly classes of ductile rumes.

(v) Even though the possibility of hinge

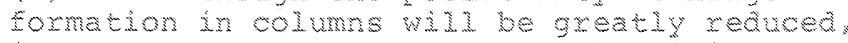
it seems prudent to retain the deta inings requirement for such colum as for those of seismic load cominated ductile frames $(7)$.

Based on the above fine considerations it is suggested that the maximum average beam overstrength factor, to be considered in the design of a gravity dommated ductine one way frames of busldings, should be approxmatery

$W_{\text {, avg.max. }} \approx 3.5 / 1.15 \mathrm{x}=3 / \mathrm{x}$

Hence for structures of Class I, II and IrI buidings(2) the approptate values of Wovg.max, axe approximately $2.0,2.5$ ard 3.0. This implies for example that the sum of the probable flexural capactures of the columns of a class I butiding so destoned woula be equal to $1.25 \times 2.6 \times 2.0=3.68$ thes the code spectided frexumal demand For a class Iry bujukng at any revex of the siructure.

The ratios of probable average flexumal colum capacties, corresponding wath the application of $\mathrm{Eq} .(9)$ axe show sn rable .

To give columme of gravity load dominated twoway Fumes ever at this hish Level of Latera 1 Loadme a sonewhat lawer degree of protection, where these are subjected to concuxant earthquake attack from both principar atrectione of the framing system, it is suggested that the approprata colum design monemt for undarm ecthona seamic Loading be kncreased by 15\%. The coxresponding average strength ratios are also shown ir rable $\mathrm{X}$. As a compaxison similar ratios of probable colum flexural capactukes. based on

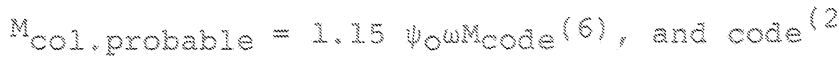


specified flexural demand, $\mathrm{M}_{\text {Code' }}$ are also presented in Table I. It should be noted that critical columns of tall, long period frames, are not likely to be gravity load dominated. Therefore the appropriate

comparison is that between columns 3 and 5, and columns 4 and 7 of Table $I$.

\section{DESIGN SHEAR FORCES}

\section{1 - Column Moments and Shears}

It was shown that beam moment inputs in gravity load dominated frames should be limited in order to prevent the column design moments from becoming excessively large. The column design moments with reference to beam centre lines are obtained $\overrightarrow{\mathrm{M}}_{\mathrm{col}}=\vec{\psi}_{i} \overrightarrow{\mathrm{M}}_{\text {code }}$

$\vec{\psi}_{i}=\frac{n \overrightarrow{\mathrm{M}}_{i}+p \overrightarrow{\mathrm{M}}_{i}}{\Delta \overrightarrow{\mathrm{M}}_{i}^{\mathrm{E}}}=\frac{\Delta \overrightarrow{\mathrm{M}}_{i} \text {, design }}{\Delta \overrightarrow{\mathrm{M}}_{i}^{\mathrm{E}}}$

and $\mathrm{M}_{\text {Code, }}$ the reference moment used throughout this proposed procedure, is the column moment derived from an elastic analysis for the code required lateral seismic loading only. The estimation of the column design moment, $\overrightarrow{\mathrm{M}}_{\mathrm{COl}}$, rests on the premise that the ratio of the critical column moments above or below a floor to each other is the same as the corresponding ratio obtained for moments of the elastic analysis. This of course is only an estimate which, because of the nature of the entire structural response, appears to be quite acceptable.

The terms of Eq. (11) have been defined previously (See also Fig. I and the Notations). The application of Eqs. (10) and (11) is illustrated in Example $I$.

To ensure ductile behaviour of the column, it is necessary to assume that, in spite of the high level of lateral loading, at least moderate column hinging might occur. Therefore the shear force across the column should be estimated from

$$
\begin{aligned}
V_{\text {col }} & =\frac{1.15}{\phi} \frac{M_{\text {col, top }}+M_{c o l} \text {, bottom }}{1} \\
& \simeq 1.35 \frac{M_{\text {col.top }}+M_{\text {col bottom }}}{I}
\end{aligned}
$$

where the factor 1.15 allows for the probable strength of the column section being attained. The capacity reduction factor $\phi$ is 0.85 . Shear reinforcement can then be provided accordingly. 8

\section{2 - Beam Shear}

It was pointed out that column hinging at its probable capacity should be considered. Accordingly beams must be assumed to absorb such increased moments wherever plastic hinges, at probable strength level of the beam have not as yet formed. Overstrength development, involving strain hardening of the reinforcing steel, is not considered in any member of this class of structure because of the high level of design loading that has been provided for.

In gravity load dominated frames the earthquake induced shear is less critical than in earthquake load dominated frames. For this reason an accurate assessment of the upper bound of this shear is not warranted. Accordingly it is suggested that the moment induced ( $\vec{E})$ critical shear force in any beam, such as span BC in Fig. $I(d)$ for example be estimated from

$v_{e}=\frac{1}{\phi I_{B C}}\left(p \vec{M}_{B}+0.9 n \vec{M}_{C}^{\circ}+0.15 \Delta \vec{M}_{B}\right.$, design $)$

where the last term makes allowance for the increase of the positive beam moment at $B$ due to a possible $15 \%$ increase of the column moments at $B$. The design shear should not need to exceed the value associated with the simultaneous formation of two plastic hinges in a span at probable strength, i.e:

$v_{e}<\frac{0.9}{\phi I_{B C}}\left(p \vec{M}_{B}^{\circ}+n \vec{M}_{C}^{\circ}\right)$

\section{AXIAL LOADS}

In gravity load dominated frames the earthquake induced axial loads on columns are also not likely to be critical quantities. Therefore precision in their evaluation is not required. At this high intensity of lateral loading it should be sufficient to estimate the earthquake induced axial loads, $P_{e q}$, from the summation of the beam shears, $\mathrm{V}_{e}$, developed at not more than 3 times the code specified lateral loading. As framed structures under consideration are not likely to have a large number of storeys, it is appropriate to assume that these beam shear forces, involving negative plastic hinge formation in each span at probable strength level, may be generated at all floors. Consequently it may be assumed in the design that

$\mathrm{P}_{\text {eq }}=\stackrel{\mathrm{n}}{\sum_{\mathrm{l}} \mathrm{V}_{\mathrm{e}}}$

where $\mathrm{n}$ signifies the number of floors above the column section considered. The shear force induced by end moments only, for example in span $C D$ of the beam shown in Fig. 1 , and considered in evaluating the earthquake induced axial compression, $\mathrm{P}_{\mathrm{eq}}$, on column $\mathrm{D}$, is therefore

$v_{e}=v_{C D}=\left(p \vec{M}_{C}+0.9 n \vec{M}_{D}^{O}\right) / I_{C D}$

\section{THE RELOCATION OF PLASTIC HINGES}

In the previous sections it was emphasised that in gravity dominated frames column design moments will become unnecessarily large if the capacity of the beam sway mechanism is to be matched. With a suitable relocation of the positive potential plastic hinge in a span, away from the column face, it is possible to introduce a deliberate and desirable weakness into the span. Thereby two plastic hinges may sometimes be formed in each span of a beam at a lateral load intensity less than $\psi_{0}$, avg.max. times code loading. This implies fuli energy dissipation in the beam mechanism without reliance on column hinging. The critical design quantities for columns, beams and joints, can therefore be reduced. This technique involves careful curtailment and anchorage of the bottom beam flexural reinforcement in the chosen potential positive plastic hinge region. 


\section{SUMMARY OF DESIGN PROCEDURE}

1) In ductile frames the moment envelopes for load combinations $\left(1.4 \mathrm{D}+1.7 \mathrm{~L}_{\mathrm{R}}\right)$ and $\left(D+1.3 L_{R}+E\right)$ need to be determined to establish the critical case for the support moment of beams.

2). Moment redistribution (3) of up to $30 \%$ should be used to minimise the potential negative moment beam capacities at interior columns, where the necessary flexural steel content is determined. To satisfy requirements for curvature ductility at these sections, at least $50 \%$ of that steel content is to be provided in the bottom of the beam section.

3) By assuming that the potential plastic hinges, as detailed, may develop at overstrength capacity at each end of all spans in a bent, the average beam overstrength factor, $\psi_{0}$, avg. (Eq. (3)) should be determined. This is a very simple procedure.

4) If it is found that $\psi_{0}$, avg. is smaller than the maximum suggested average beam overstrength factor, $\psi_{\text {o, avg.max. }}=\frac{3}{\bar{I}}$, the evaluation of column moments can $\bar{I}$ proceed as for typical earthquake load dominated frames $(6)$.

In the opposite case the columns should be designed to resist moment input from beams equal to $\frac{3}{T}$ times that required by lateral code $\bar{I}$ loading as follows:

(a) Evaluate the probable flexural capacities, $0.9 n \vec{M}_{i}^{O}$, in potential negative plastic hinge localities of all spans.

(b) Compute from Eq. (4) the total moment in the bent to be supplied by the potential positive plastic localities, $\sum \overrightarrow{p M}_{i}$.

(c) Compute from Eq. (5) the total required reduction of the negative gravity moments in those localities, $x$.

(d) Distribute this moment, $\mathrm{x}$, among all beams of the bent in proportion of the beam stiffnesses and obtain the net design moment, $\mathrm{pM}_{i}$, in the relevant ends of the spans from $\mathrm{Eq} \cdot(7)$.

(e) Check that a moment so computed does not exceed the probable capacity of any potential positive plastic hinge, and if necessary re-allocate the excess moment, $\Delta \mathrm{X}$, in accordance with Eqs. (7) and (8), to other spans with only one plastic hinge.

5) From the beam moments found determine the column design moments using Eqs. (10) and (1I). These are $\mathrm{M}_{\mathrm{CO}}$, top or $\mathrm{M}_{\mathrm{Col}}$, bottom.

6) Estimate the column shear forces from Eq. (12) and the beam shear forces from Eq. (13) or Eq. (14).

7) Evaluate the column axial load from the appropriate gravity forces and the accumulation of earthquake induced beam shear forces in accordance with Eqs. (15) and $(16)$.

8) Design the column section to possess an ideal capacity to resist the moment derived in 5) and the axial forces obtained in 7).

The application of these design steps is illustrated in the Appendix.

\section{ACKNOWLEDGEMENT}

A critical examination by users of the design techniques suggested in Ref. (6) and mainly intended for medium to high-rise ductile reinforced concrete frames in which usually seismic criteria govern the design strength of members, prompted the writer to study design features in gravity load dominated frames. The helpful observations and suggestions of K. E. Williamson, N. W. Allardice, A. L Andrews, L. M. Robinson and B. W. Buchanan, within the deliberations of a study group of the New Zealand National Society for Earthquake Engineering $(9)$, is greatfully acknowledged. The views held and the proposals made in the paper are, however, those of the author alone.

\section{REFERENCES}

1. Smith, I. C. and Sidwell, G. K., "Seismic Design of Ductile Moment Resisting Reinforced Concrete Frames - Beam Flexure and Hinge Zone Detailing in Reinforced Concrete Ductile Frames Requiring Beam Sway Mechanisms", Bulletin of the New Zealand National Society for Earthquake Engineering, Vol. 10, No. 2, June 1977, pp. 72-79.

2. NZS 4203:1976, New Zealand Standard Code of Practice for General structural Design and Design Loading for Buildings, Standards Association of New Zealand, $80 \mathrm{pp}$.

3. Paulay, T., "Moment Redistribution in Continuous Beams of Earthquake Resistant Multistorey Reinforced Concrete Frames", Bulletin of the New Zealand National Society for Earthquake Engineering, Vol. 9, No. 4, Dec. 1976, pp. 205-212.

4. Park, R. and Paulay, T., "Reinforced Concrete Structures", John Wiley and Sons, New York, 1975, 669pp.

5. ACI Committee 318, "Building Code Requirements for Reinforced Concrete (ACI 318-71)", American Concrete Institute, Detroit, 1977, 78pp.

6. Paulay, T., "Seismic Design of Ductile Moment Resisting Reinforced Concrete Frames - Columns - Evaluation of Actions" Bulletin of the New Zealand National Society for Earthquake Engineering, Vol. 10, No. 2, June 1977, pp.86-94.

7. Park, R., "Seismic Design of Ductile Moment Resisting Reinforced Concrete Frames - Columns Subjected to Flexure and Axial Load", Bulletin of the New Zealand National Society for Earthquake Engineering, Vol. 10, No. 2, June 1977, pp.95-101.

8. Paulay, T., "Seismic Design of Ductile Moment Resisting Reinforced Concrete Frames - Shear Strength Requirements" Bulletin of the New Zealand National Society for Earthquake Engineering, Vol. 10, No. 2, June 1977, pp.80-84.

9. Burns, R. J., "Seismic Design of Ductile Moment Resisting Reinforced Concrete Frames - Introduction and Philosophy". Bulletin of the New Zealand National Society for Earthquake Engineering, Vol. 10, No. 2, June 1977, pp.69-71.

11. NOTATION

$$
D=\text { dead load }
$$




$$
\begin{aligned}
& E \text { = earthquake load } \\
& I=\text { second moment of area of section } \\
& \mathrm{k}=\text { relative flexural stiffness } \\
& 1=\underset{c}{\text { centre to centre length of }} \text { mer } \\
& L=\text { live load } \\
& \mathrm{M}=\text { bending moment } \\
& \mathrm{M}_{\text {code }}=\text { column bending moment from code }
\end{aligned}
$$

Subscripts and superscripts

$A, B, C, \ldots i=$ refers to column or joint at $A, B, C, \ldots$ i

$E=$ refers to action due to earthquake

$\mathrm{G}=$ refers to action due to gravity load

$0=$ refers to flexural overcapacity

$\mathrm{n}=$ refers to a negative beam moment involving tension in top

$\mathrm{P}=$ refers to a positive beam moment involving tension in bottom flexural reinforcement

$\mathrm{R}=$ refers to reduced quantities such as live load

$\rightarrow=$ refers to the direction of lateral load

Paper received 18 January, 1978,

\section{APPENDIX}

\section{Example 1}

I.1 - Fig. 2(a) shows the beam bending moment pattern for the load combination $\left(1.4 \mathrm{D}+1.7 \mathrm{~L}_{\mathrm{R}}\right)$ and relevant to three spans of a symmetrical frame for a class III building. The moments

\begin{tabular}{|c|c|c|c|}
\hline & & $\begin{array}{l}\text { At A } \\
\text { and D }\end{array}$ & $\begin{array}{l}\text { At } B \\
\text { and } C\end{array}$ \\
\hline \multirow{2}{*}{$\begin{array}{l}\text { Dependable flexural } \\
\text { capacity }\end{array}$} & Negative & 140 & 190 \\
\hline & Positive & 70 & 95 \\
\hline \multirow{2}{*}{$\begin{array}{l}\text { Overstrength flexural } \\
\text { capacity* }\end{array}$} & Negative & 195 & 264 \\
\hline & Positive & 97 & 132 \\
\hline
\end{tabular}
obtained from an elastic analysis have been redistributed, as shown with the dashed curve, so that the critical exterior and interior negative moments become 140 and 190 moment units respectively. For the purpose of this illustrative example again centre line moments are considered, rather than moments at the faces of columns or beams that should be used in the design of the structure.

I.2 - Fig. 2(b) and (c) show the moments for the load combination $\left(D+1.3 L_{R}\right)$ and earthquake (E), both obtained from elastic analyses. It is evident that, with only limited moment redistribution $(3)$ of the combined earthquake and gravity moments $\left(D+1.3 L_{R}+\vec{E}\right)$, the critical design moments could be made everywhere less than those obtained in I.I.

I.3 - It will now be assumed that the dependable flexural capacities, provided by the designer at all supports, are exactly those required by the moments of Fig. $2(a)$. To satisfy detailing requirements for sectional ductility, exactly $50 \%$ of these negative moment capacities have been provided at the ends of the spans for positive moments (i.e. bottom flexural reinforcement). Hence the relevant flexural capacities of the beam, as detailed, are in moment units as follows:

* Overstrength $\simeq 1.39$ Dependable Capacity

I.4 - The required lateral load resistance of the three span beam for earthquake loading, shown in Fig. 2(c), is from Eq. (1).

$\sum \Delta \vec{M}_{i}^{E}=40+(40+30)+(30+40)+40=220$ units

I.5 - The potential overcapacity of the entire bent, with respect to earthquake loading, is obtained from Eq. (2) and the table above, thus:

$$
\begin{aligned}
\sum \Delta \vec{M}_{i}^{\circ}=97 & +(264+132)+(264+132)+195 \\
& =1084 \text { units }
\end{aligned}
$$

The moment pattern corresponding with this state of overcapacity is shown by the dashed curves in Fig. 2(d). It is seen that not only do large moment inputs from beams to columns occur, particularly at interior columns, but the positive bending moments within each span that would need to be resisted, are also very large.

I.6 - The average overstrength factor for the entire bent is thus from Eq. (3)

$\vec{\psi} 0_{0}$ avg. $=1084 / 220=4.93$

It indicates that the beams, as detailed, are capable at overstrength capacity to resist $493 \%$ of the code required lateral earthquake load. This is clearly in excess of the value suggested in Eq. (9) i.e. $\psi \circ, \mathrm{avg} \cdot \max =3.0$.

I.7 - It may now be assumed that only the 
flexural strengths of the negative moment hinges $(0.9 \mathrm{nM})$ for $\bar{E}$ loading at $B, C$ and $D$ are developed. Therefore the sum of the moments in the potential positive hinge localities, $\left(\mathrm{p} \vec{M}_{j}\right)$, at the opposite ends of the spans, need only be from Eq. (4)

$$
\begin{aligned}
& \sum \overrightarrow{\mathrm{M}}_{i}=\psi_{0}, \operatorname{avg} \cdot \max { }_{0} \sum \Delta \overrightarrow{\mathrm{M}}_{i}^{\mathrm{E}}-0.9 \sum \mathrm{nM} \overrightarrow{\mathrm{M}}_{i}^{\mathrm{O}} \\
&=3 \times 220-0.9(264+264+195)=9.3 \\
& \text { units }
\end{aligned}
$$

I.8 - The required total reduction of the negative gravity moments in the potential positive plastic hinge localities ( $\mathrm{pM}_{i}^{G}$ ) at $A, B$ and $C$, as shown in Fig. 2(b) will be from Eq. (5)

$$
\begin{aligned}
\overrightarrow{\mathrm{X}} & =\sum \overrightarrow{\mathrm{M}}_{i}-\sum \mathrm{pM} \mathrm{i}_{i}^{\mathrm{G}}=9.3-(-100-170-140) \\
& =419.3 \text { units }
\end{aligned}
$$

I.9 - The final moments, which need be developed at the potential positive hinge locations at $A, B$ and $C$, are therefore obtained from Eq. (6) i.e.

$\vec{p}_{i}=\mathrm{pM}_{i}^{G}+\frac{\mathrm{k}_{i}}{\sum \mathrm{k}_{i}} \overrightarrow{\mathrm{x}}$

As the beams are prismatic but of varying length, as shown in Fig. 2(c), the stiffness ratios for the three spans will be $0.37,0.26$, 0.37 respectively. Therefore from Eq. (6)

$$
\begin{aligned}
& \overrightarrow{p M}_{A}=-100+0.37 \times 419.3=55.1 \text { units }<0.9 \times 97 \\
& =87.3 \text { units }
\end{aligned}
$$

$\overrightarrow{\mathrm{PM}}_{\mathrm{BC}}=-170+0.26 \times 419.3=-60.9$ units (did not change to positive)

$\mathrm{pM}_{\mathrm{CD}}=-140+0.37 \times 419.3=15.1$ units $<0.9 \times 132$ $=118.8$ units

The total is 9.3 units as required in 1.7 .

It is seen that the probable positive flexural capacities are not approached by the required moments, and that at column $B$ the moment remains negative. The corresponding moment pattern is shown in Fig. 2(d) by the full line curves.

To check the moment calculations Eq. (4*) may be used thus:

$$
\begin{gathered}
(55.1-60.9+15.1)+0.9(264+264+195) \\
=660=3 \times 220 \text { units }
\end{gathered}
$$

I.10 - The columns design mornents at the beam centre lines may now be determined. These represent the ideal column flexural capacity required which should not be less than $\mathrm{M}_{\mathrm{CO}}$ $=\psi_{i} M_{c o d e} \mathrm{Eq}$. (10), where $\mathrm{M}_{\text {code }}$ is the column bending moment above or below the beam centre line, obtained from an elastic frame analysis for the code specified lateral (E) load only( $(6)$, as shown in Fig. 2(c), and where $\psi_{i}$ is from Eq. (II).

$$
\begin{aligned}
& \text { at } \operatorname{Col} . A=55.1 / 40 \quad=1.38 \\
& \text { at Col. } B=(0.9 \times 264-60.9) /(40+30)=2.53 \\
& \text { at Col. C }=(0.9 \times 264+15.1) /(30+40)=3.61 \\
& \text { at } \mathrm{Col} . \mathrm{D}=0.9 \times 195 / 40=4.39
\end{aligned}
$$

Therefore the design centre line moments for the columns immediately above the floor under consideration will be from Fig. 2 (c) and
Eq. (10)

$$
\begin{aligned}
& \text { at } A=1.38 \times 25=34.5 \text { units } \\
& \text { at } B=2.53 \times 35=88.6 \text { units } \\
& \text { at } C=3.61 \times 35=126.4 \text { units } \\
& \text { at } D=4.39 \times 25=\frac{109.8 \text { units }}{359.3 \text { units }}
\end{aligned}
$$

The ideal column strengths so obtained may be compared with the flexural requirements of the code loading, Fig. 2(c), at this level, i.e.

$359.3 /(25+35+35+25)=2994 \approx 3.0$

I.11 - The dependable moment induced beam shear forces in the centre span, which would need to be combined with the appropriate gravity shears, computed for the simply supported span, would be from Eq. (13) and Fig. $2(a)$

$$
\begin{aligned}
\phi \vec{V}_{e} & =\left(p \vec{M}_{B}+0.9 n \vec{M}_{C}^{0}=0.15 \Delta \vec{M}_{B}, \operatorname{design}\right) / 1= \\
& =(-61+0.9 \times 264+0.15(238-61) / 1= \\
& =203 / 1
\end{aligned}
$$

but according to Eq. (14) not larger than

$$
\begin{aligned}
\phi \vec{V}_{e} & <0.9\left(p \overrightarrow{\mathrm{M}}_{\mathrm{B}}^{\circ}+\mathrm{n} \overrightarrow{\mathrm{M}}_{\mathrm{C}}^{\circ}\right) / 1= \\
& =0.9(132+264) / 1=356 / 1>203 / 1
\end{aligned}
$$

Similarly for span $\mathrm{AB}$ :

$$
\begin{aligned}
\phi \vec{V}_{e} & =(55+0.9 \times 264+0.15 \times 97) / 0.71= \\
& =439 / 1
\end{aligned}
$$

but not larger than

$$
0.9(264+97) / 0.71=464 / 1>439 / 1
$$

and in span $C D$ :

$$
\begin{aligned}
\phi \vec{V}_{e} & =(15+0.9 \times 195+0.15(238+15)) / 0.71= \\
& =326 / 1
\end{aligned}
$$

but not larger than

$0.9(132+195) / 0.71=420 / 1>326 / 1$

Example II

II.1 - The code specified earthquake moments for the beams only of a two-bay ductile frame are shown in Fig. 3(a). It is a Class III building with $I=1.0$.

II.2 - In evaluating the lateral load strength of the two-span beam the end moments shown in Table II, in correspondingly labelled lines, have been considered as follows:

(a) The end-moments due to the load combination $\left(D+1.3 L_{R}\right)$ were derived from an elastic analysis. These moments, shown by line 1 in Fig. 3 (b) are conveniently combined with the span moments for the freely supported beam, shown by the curve. In this diagram, which lends itself more readily to combine all seismic load combinations (3), areas above the curves signify positive moments and, conversely, areas below the curves represent negative moments, requiring top 
beam reinforcement. The derivation of the final moments is achieved simply by suitable adjustment of straight lines, connecting end-moments.

(b) The superimposing of gravity and earthquake moments $\left(D+1.3 L_{R}+E\right)$ gives values that are considered first. The appropriate moment pattern, with reference to the curves as the base lines, is given by line 2 in Fig. 3(b).

(c) The combination of ( $\left.D+1.3 L_{R}+\overleftarrow{E}\right)$ is shown in the Table but, for the sake of clarity, not in Fig. $3(b)$.

(d) After allowing for some moment redistribution, and noting that the load combination $\left(1.4 \mathrm{D}+1.7 \mathrm{~L}_{\mathrm{R}}\right)$ did not produce larger support moments, the design moments for dependable strength at the supports have been determined and these are recorded in line (d) of Table II. It is again assumed, as in Example $I$, that these strengths have been provided and that the positive moment capacity at each support is one half of the negative moment capacity there.

(e) The overstrength capacities of the four sections, for both negative and positive moments, are simply 1.39 times the dependable capacities. If such moments were to be developed, line 3 in Fig. 3 (b) would have to be used when considering $\vec{E}$ loading. This would involve considerably moment input into collumn B.

(f) For convenience the probable (hinge) capacities, taken as 0.9 times the overstrength, of the sections are also recorded.

II.3 - The analysis may now proceed and from Eq. (1) and Fig. $3(a)$ it is found that

$\sum \Delta \vec{M}_{i}^{E}=18+20+15+15=68.0$ units

From Eq. (2) and Table II, line e, the overstrength of the beam sway mechanism is found to be

$\Sigma \Delta \overrightarrow{\mathrm{M}}_{i}^{\circ}=26.4+(111.2+55.6)+83.4=276.6$ units

and hence from Eq.

$\psi_{0, \text { avg. }}=276.6 / 68.0=4.07$ which is larger than 3:0 given by Eq. (9), and hence the frame is gravity load dominated.

II. 4 - The positive moments that need to be developed at the left hand supports of the beams, to sustain 3 times the code (Iateral) loading while the probable negative hinge moment at the right hand ends of the spans develop, is found from Eq. (4) thus:

$\sum \vec{p}_{i}=3 \times 68.0-0.9(111.2+83.4)=28.9$

Therefore the sum of the positive moments to be applied to the left hand supports is from Eq. (5)

$\overrightarrow{\mathrm{x}}=28.9-(-20-80)=128.9$ units

which can now be distributed among the two beams in accordance with Eq. (6). The relative stiffness of the two prismatic beams are 0.57 and 0.43 respectively.
II.5 - The final moments (positive) at the left hand ends of the spans are from Eq. (6) as follows.

at $A \overrightarrow{p M}_{A}=-20.0+0.57 \times 128.9=53.5$ units

However, as line $f$ of Table II shows, the probable hinge capacity at this location is only 23.8 units. Therefore $53.5-23.8=$ 29.7 units need be redistributed to the potential positive hinge(s) of the other span(s). Therefore from Eq. (8)

at $\mathrm{B} \overrightarrow{\mathrm{M}}_{\mathrm{B}}=-80.0+0.43 \times 128.9+\frac{I}{I} \begin{gathered}29.7=5.1 \\ \text { units }\end{gathered}$

which can be comfortably accommodated, i.e. $5.1 \ll 50.0$.

The final bending moments, which need to be developed before the supporting columns are permitted to yield, are thus found and the heavy line (F) in Fig. 3(b) shows these. The large positive moment at the centre of the long span is less than the moment due to $\left(1.4 \mathrm{D}+1.7 \mathrm{~L}_{\mathrm{R}}\right)$ combination at the same section.

As a check Eq. (4a) may be applied, i.e.

$(23.8+5.1)+(100.0+75.1)=204$ units and

$$
3 \times 68=204 \text { units }
$$

II.6 - Without providing further comments the same procedure will be repeated for the case when the earthquake load acts from the other direction, i.e. E;

(i) From Eq. (1) $\sum \Delta \overleftarrow{\mathrm{M}}_{i}^{\mathrm{E}}=-68.0$ units

(ii) From Eq. (2)

$\sum \Delta \overleftarrow{M}_{i}^{O}=-52.8-55.6-111.2-41.7=\begin{gathered}-261.3 \\ \text { units }\end{gathered}$

(iii) $\psi_{0, \text { avg. }}=-261.3 /-68=3.84>3.0$

(iv) From Eq. (4)

$\Sigma \mathrm{p}_{i}^{\overleftarrow{M}_{i}}=-3 \times 68-0.9(52.8+111.2)=56.4$ units

(v) From Eq. (5) $\overleftarrow{\mathrm{X}}=56.4-(-60-40)=156.4$ units

(vi) From Eq. (6)

$\mathrm{p}_{\mathrm{C}}^{\overleftarrow{\mathrm{C}}_{\mathrm{C}}}=-440.0+0.43 \times 156.4=27.3<37.6$ units $\mathrm{p}_{\mathrm{B}}^{\overleftarrow{\mathrm{M}}_{\mathrm{B}}}=-60.0+0.57 \times 156.4=29.2<50.0$ units

These moments are shown by the dashed straight line marked $\mathrm{E}$ in Fig. $3(\mathrm{~b})$

$$
\begin{array}{r}
\text { (vii) Check }-47.5-29.2-100.0-27.3=-204 \\
\text { units } \\
-3 \times 68 \quad \begin{array}{c}
=-204 \\
\text { units }
\end{array}
\end{array}
$$

\section{Example III}

III.1 - A typical interior span of a long uniform and symmetrical bent of a ductile frame, shown in Fig. 4(a), is considered to illustrate behaviour and design consideration only. Because of the identical nature of the spans all previously discussed 
factors apply only to one bay of this frame.

III.2 - The uniformly distributed dead load, $D$, on each $\operatorname{span}$ is $w=29.2 \mathrm{kN} / \mathrm{m}$. The reduced live load, $L_{R}$, is one half of that, i.e. $14.6 \mathrm{kN} / \mathrm{m}$.

The negative support moments are assumed to be as follows:

$M_{D}=0.6 \mathrm{wI}^{2} / 8=0.6 \times 29.2 \times 9.15^{2} / \underset{\mathrm{kNm}}{/ 8}=183$

Therefore these moments are for the following load combinations:

$$
\left(1.4 \mathrm{D}+1.7 \mathrm{~L}_{\mathrm{R}}\right), \mathrm{M}=2.25 \times 183=412 \mathrm{kNm}
$$

$$
\left(D+1.3 L_{R}\right), M=1.65 \times 183
$$

(iii) 0.90 ,

$M=0.90 \times 183$

$=165 \mathrm{kNm}$

III.3 - The earthquake design moments, $\vec{E}$, at the ends of the members meeting at a joint are all $100 \mathrm{kNm}$ as shownin Fig. 4(a).

III. 4 - The critical design moments at the supports are therefore either

for $\left(1.4 D+1.7 L_{R}\right)=$

or for $\left(D+1.3 L_{R}+\vec{E}\right)=302+100=402 \mathrm{kNm}$

It is assumed that the strengths provided (in $\mathrm{kNm}$ units) in the beam are as follows:

(a) Dependable capacity : -412 and +206

(b) Probable capacity : -516 and +258

(c) Overcapacity : -572 and +286

In Fig. 4 (b) curve (1) shows the moment pattern required for the code $\left(D+I .3 L_{R}+\vec{E}\right)$ loading, while curve (2) indicates the moments that would be generated if both end-hinges develop overcapacities.

III. 5 - From the beam overcapacities and Eq. (3) it is evident that

$\psi_{\text {o, avg. }}=\frac{572+286}{100+100}=\frac{858}{200}=4.29>3.00$

Therefore from Eq. (4) for this simple span

$\mathrm{p}_{\mathrm{A}}=3.0 \times 200-516=84<258 \mathrm{kNm}$

giving the maximum positive (elastic) moment to be designed for in terms of input into the column. The corresponding beam moments are shown by curve (3) in Fig. $4(\mathrm{~b})$.

III. 6 - From Eq. (11), when applied to column B,

$\vec{\psi}_{B}=\frac{516+84}{200}=3.00$ and from Eq.

$\overrightarrow{\mathrm{M}}_{\mathrm{COI}}=\psi_{B}{ }_{\text {code }}=3.0 \times 100=300 \mathrm{kNm}$

III.7 - The critical moment induced shear in the beam will be from Eq. (13)

$v_{e}=(84+516+0.15 \times 600) / 0.85 \times \underset{k N}{9.15}=88.7$ indiscriminate application of capacity design, i.e.;

$\mathrm{v}_{e}^{\circ}=(572+286) / 0.85 \times 9.15=110.3 \mathrm{kN}$

therefore the critical shear, including gravity, is:

$\mathrm{V}_{\mathrm{B}}=88.7+0.5 \times 9.15 \times(1.65 \times 292) \underset{\mathrm{kN}}{=309.1}$

III.8 - Assuming that the floor heights in this regular structure are $3.5 \mathrm{~m}$, the column design shear would be from Eq. (12):

$\mathrm{v}_{\text {col. }}=1.35(300+300) / 3.5=231.4 \mathrm{kN}$ This is $405 \%$ of the column shear required by code loading i.e. $200 / 3.5=57.2 \mathrm{kN}$.

III.9 - Finally an alternative solution, based on a relocated potential positive plastic hinge, is illustrated with the aid of Fig. 4(c). Curve I shows the moment pattern for gravity $\left(1.4 \mathrm{D}+1.7 \mathrm{~L}_{R}\right)$ load and used to allocate the flexural reinforcement in various parts of the beam. The bottom (positive) beam reinforcement could be curtailed so that near the point of contraflexure the dependable flexural capacity reduces to $275 / 3=92 \mathrm{kNm}$. It will therefore be assumed that the overstrength and dependable capacities respectively at 2.0 metres from support $A$ and at section $B$ are as follows:

at (C) $1.39 \times 92 \approx 130 \mathrm{kNm}$ and $0.9 \times \begin{gathered}130=117 \\ \mathrm{kNm}\end{gathered}$

at (B) $1.39 \times 412=572 \mathrm{kNm}$ and $0.9 \times 572=$ $516 \mathrm{kNm}$

From curve (II) of Fig. 4(c) it is seen that the development of overstrength at these two potential plastic hinges results in $\phi_{0}$ avg $=(572-102) / 200 \equiv 2.35$ when the combination of $\left(D+1.3 L_{R}=\vec{E}\right)$ is considered. This load, however, will not produce the maximum earthquake induced column moments. If the combination $(0.9 \mathrm{D}$ $+\vec{E})$ is considered, the plastic hinge development at probable strength will give rise to the moments shown by curve III in Fig. 4 (c) and therefore

$\phi_{0, \text { avg. }}=(516+52) / 200=2.82 \approx 3.0$

This represents very close to the maximum that was envisaged in this paper.

The advantages of this arrangement are:

(1) Energy dissipation can be retained in the beams in two plastic hinges that are not subjected to reversed yielding.

(2) The positive (bottom) reinforcement in the span need not be increased above that required for gravity $\left(1.4 \mathrm{D}+1.7 \mathrm{~L}_{\mathrm{R}}\right)$ loading only. 
TABLE I .

RATIO OF PROBABLE AVERAGE COLUMN FLEXURAL CAPACITIES

TO CODE ${ }^{(2)}$ SPECIEIED FLEXURAL DEMAND AT A LEVEL*

\begin{tabular}{|c|c|c|c|c|c|c|c|}
\hline \multicolumn{2}{|l|}{. } & \multicolumn{2}{|c|}{ Gravity dominated } & \multicolumn{4}{|c|}{ Seismic load dominated ${ }^{2}$} \\
\hline Class & $I^{I}$ & $\begin{array}{c}\text { One-way } \\
\text { frames }\end{array}$ & $\begin{array}{l}\text { Two-way } \\
\text { Exames }\end{array}$ & $\begin{array}{l}\text { One-way } \\
\text { min }\end{array}$ & $\begin{array}{l}\text { frames } \\
\max ^{4}\end{array}$ & $\begin{array}{c}\text { Two-way } \\
\min ^{3}\end{array}$ & $\begin{array}{c}\text { frames } \\
\max ^{4}\end{array}$ \\
\hline 1 & 2 & 3 & 4 & 5 & 6 & 7 & 8 \\
\hline$I$ & 1.6 & 3.68 & 4.23 & 3.07 & 4.60 & 3.84 & 4.86 \\
\hline II & 1.3 & 3.74 & 4.30 & 2.50 & 3.75 & 3.12 & 3.96 \\
\hline III & 1.0 & 3.45 & 3.97 & 1.92 & 2.88 & 2.40 & 3.04 \\
\hline
\end{tabular}

* The probable capacity is assumed to be 1.15 times the ideal strength or 0.9 times the overcapacity.

1. Importance factor (2)

2. It is assumed that optimum design was used and that for this reason the beam overstrength factor used in seismic load dominated frames is uniformly 1.39. Thus the appropriate ratios are obtained from (1.15) (1.39) $\omega$.

3. The minimum value of the dynamic magnification factor, $\omega$, corresponds with a fundamental period of vibration of $\mathrm{T}<0.5$ seconds.

4. The maximum value of $w$ corresponds with $T>1.6$ seconds $(6)$. Gravity load dominated frames are not likely to be in that range.

TABLE II

END-MOMENTS FOR THE EXAMPLE STRUCTURE II

\begin{tabular}{|c|c|c|c|c|c|}
\hline & \multirow{2}{*}{ Cause of moment } & \multicolumn{4}{|c|}{ Moments* at (in moment units) } \\
\hline & & A & $\mathrm{BA}$ & $\mathrm{BC}$ & $\mathrm{C}$ \\
\hline a & $\mathrm{D}+1.3 \mathrm{~L}_{\mathrm{R}}$ & -20.0 & -60.0 & -80.0 & -40.0 \\
\hline b & $D+1.3 I_{R}+\vec{E}$ & +2.0 & -80.0 & -65.0 & -55.0 \\
\hline C & $\mathrm{D}+1.3 \mathrm{~L}_{\mathrm{R}}+\stackrel{\leftarrow}{\mathrm{E}}$ & -38.0 & -40.0 & -95.0 & -25.0 \\
\hline $\mathrm{d}$ & Design moments (dependable) & -38.0 & -80.0 & -80.0 & -60.0 \\
\hline e & $\begin{array}{ll}\text { Overstrength } & \text { (negative) } \\
\text { Overstrength (positive) }\end{array}$ & $\begin{array}{r}-52.8 \\
26.4\end{array}$ & $\begin{array}{r}-111.2 \\
55.6\end{array}$ & -111.2 & $\begin{array}{r}-83.4 \\
41.7\end{array}$ \\
\hline $\mathbf{f}$ & $\begin{array}{l}\text { Probable strength (negative) } \\
\text { Probable strength (positive) }\end{array}$ & $\begin{array}{r}-47.5 \\
23.8\end{array}$ & $\begin{array}{r}-100.0 \\
50.0\end{array}$ & $\begin{array}{r}-100.0 \\
50.0\end{array}$ & $\begin{array}{r}-75.1 \\
37.6\end{array}$ \\
\hline
\end{tabular}

* In this sign convention negative moments require top and positive moments require bottom flexural reinforcement in the beams. 


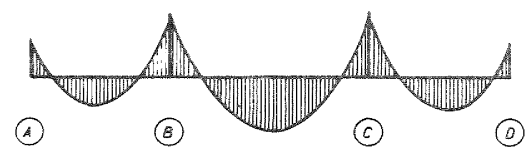

(a) MOMENTS FOR $0+1.3 L_{R}$

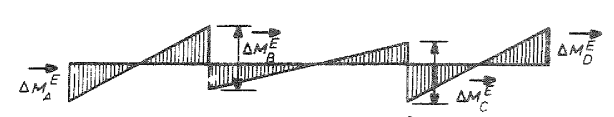

(b) MOMENTS FOR $\vec{E}$
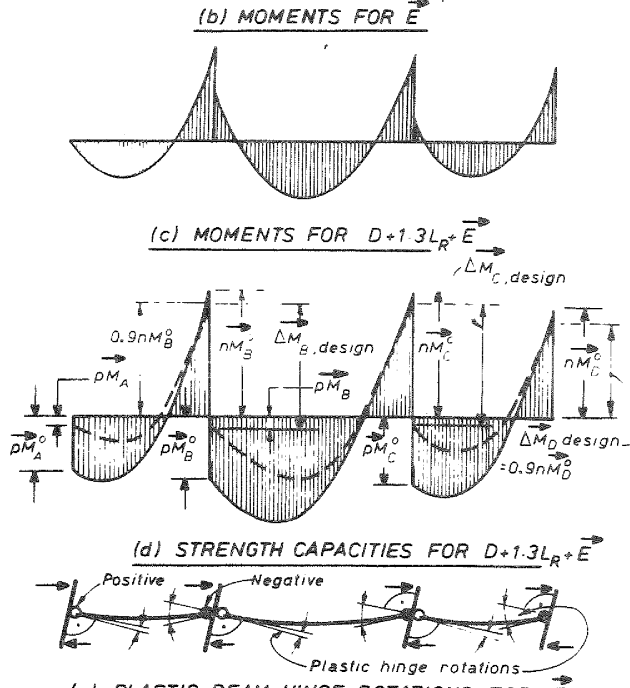

(e) PLASTIC BEAM HINGE ROTATIONS FOR $\vec{E}$

FIGURE 1: BEAM MOMENT PATTERNS FOR A THREE BAY SYMMETRICAL BENT

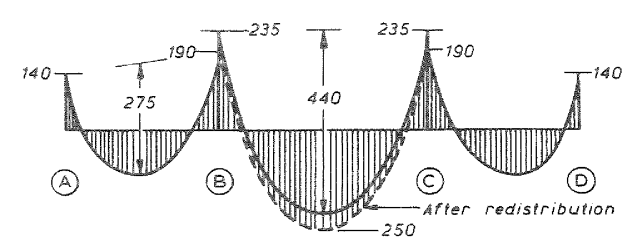

(2) MOMENTS FOR $1.40+1.7 L R$

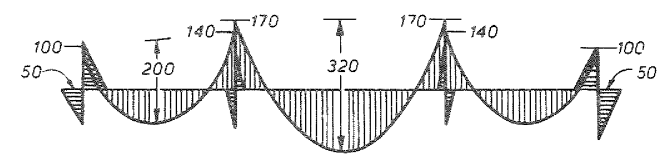

(D) MOMENTS FOR D+1.3LR

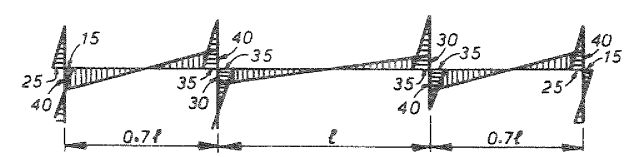

(c) MOMENTS FOR $\vec{E}$

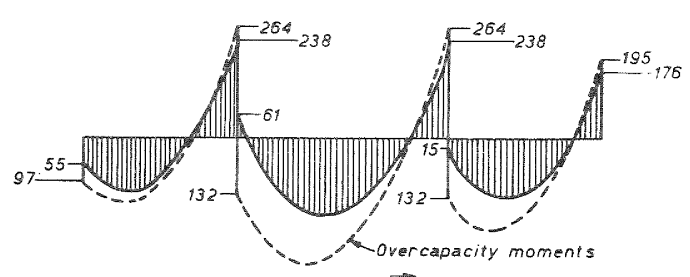

(d) MOMENTS FOR $D+1.3 L_{R} \cdot \overrightarrow{E^{O}}$

FIGURE 2: BENDING MOMENTS

FOR THE EXAMPLE STRUCTURE I

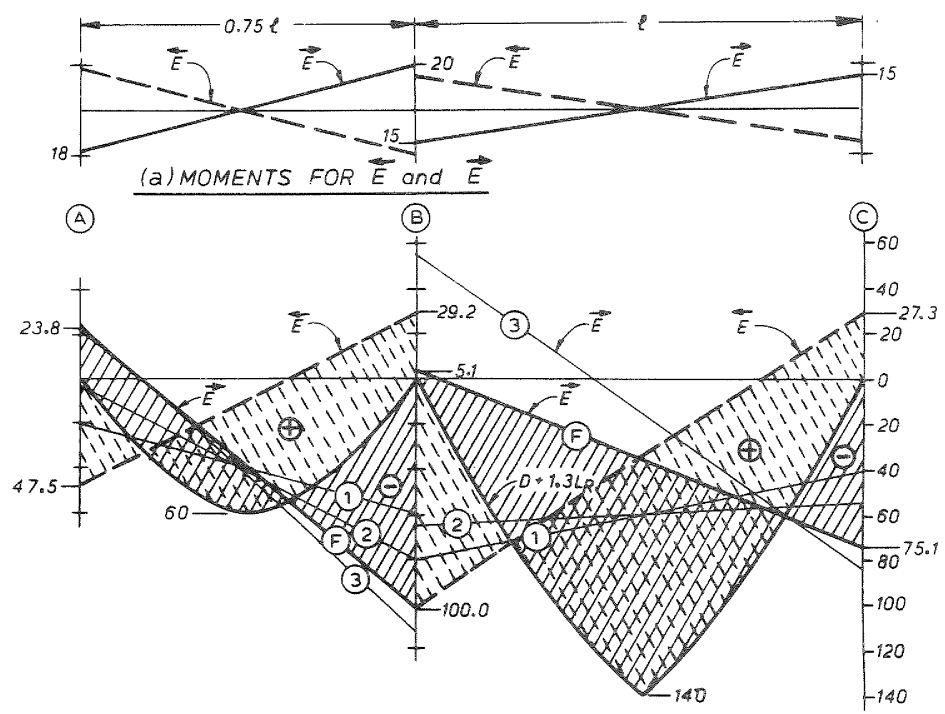

(b) MOMENTS FOR $D+1.3 L_{R}+\vec{E}$ or $\vec{E}$

FIGURE 3: BENDING MOMENTS FOR

THE EXAMPLE STRUCTURE II
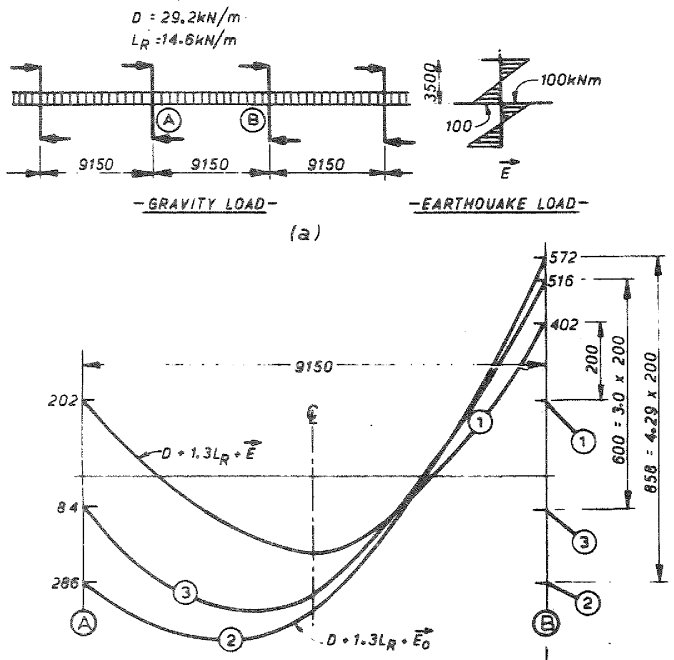

(b)

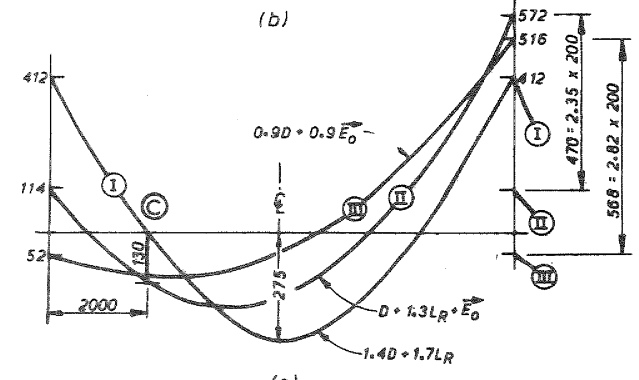

(c)

FIGURE 4: LOADING AND BENDING MOMENTS FOR THE EXAMPLE STRUCTURE III 